\title{
Knowledge, attitude and practice towards medicines among school teachers in Lalitpur district, Nepal before and after an educational intervention
}

Nisha Jha ${ }^{1 *}$, Omi Bajracharya ${ }^{3}$ and P Ravi Shankar ${ }^{2}$

\begin{abstract}
Background: Few studies regarding Knowledge, Attitude and Practice (KAP) towards medicines among school teachers have been carried out in Nepal. Obtaining baseline KAP is important to note deficiencies and plan appropriate interventions. School teachers have to know about medicines as they can be an important source of information about rational and safe use of medicines. The department of Clinical Pharmacology, KIST Medical College, Lalitpur, conducted a study regarding KAP of school teachers about medicines before and after an educational intervention from April 2011 to December 2011.
\end{abstract}

Methods: The study was done in selected schools of Lalitpur district. Teachers were selected on a voluntary basis after obtaining written informed consent. Gender, ethnic or caste group, native place, age, educational qualifications, subject taught were noted. An educational intervention using a combination of methods like presentations, brainstorming sessions, interactive discussions using posters and distribution of information leaflets about the use of medicines was conducted. The KAP and overall scores among subgroups according to gender, age, level of education, subject, ethnicity, type of school (primary vs. secondary and government vs. private school) were studied. KAP and overall scores before and after the intervention was compared using Wilcoxon signed ranks test as the scores were not normally distributed.

Results: A total of 393 teachers participated before and after the intervention. The median (interquartile range) knowledge, attitude and practice scores before the intervention were 63 (10), 23 (5) and 270 (48) respectively while the overall score was 356. The median knowledge, attitude and practice scores after the intervention were 71 (10), 28 (5) and 270 (48) respectively while the overall score increased to 369. Maximum possible score of knowledge, attitude and practice were 100, 40 and 320 respectively. Scores improved significantly for knowledge $(p<0.001)$, attitude $(p<0.001)$ and total scores $(p<0.001)$ but not for practice $(p=0.528)$.

Conclusion: The intervention was effective in improving knowledge and attitude of the teachers. More studies among school teachers about their knowledge, attitude and practice about medicines are required in Nepal.

Keywords: Attitude, Children, Knowledge, Medicines, Nepal, Practice, School

\footnotetext{
* Correspondence: nishajha32@gmail.com

'Department of Clinical Pharmacology \& Therapeutics Department of Clinical

Pharmacology \& Therapeutics, KIST Medical College, Imadol, Nepal

Full list of author information is available at the end of the article
} 


\section{Background}

Almost half of all medicines globally are used irrationally. This can have severe consequences: adverse drug reactions, drug resistance, protracted illness and even death [1]. In addition, the financial cost incurred by individuals and governments due to irrational use is unnecessary and often extremely high, particularly in developing countries where patients often pay for medicines out of their own pockets [1]. Irrational use of medicines includes overtreatment of a mild illness, inadequate treatment of a serious illness, misuse of anti-infective drugs, over-use of injections, self-medication of prescription drugs and premature interruption of treatment. Data from many countries shows that such practices are frequent, and not exclusive to developing countries [1-3].

According to figures gathered by surveys presented to the World Health Organization (WHO) in 2000, about $60 \%$ of antibiotics in Nigeria were prescribed unnecessarily. In Nepal, over $50 \%$ of antibiotics prescribed in 1996 were not needed and $40 \%$ of medicines expenditure in the same year was wasted due to inappropriate prescriptions. Globally, the figure for unwarranted antibiotic prescriptions stands at roughly $50 \%[1,2]$.

Schools are considered a second home in Nepal, where students spend a large percentage of their time during childhood and adolescence. These days, students spend about seven to nine hours five or six days a week at school. The first place of learning is considered to be the home, where one is born and grows up with ones parents. School is the second place where the child learns how to interact, behave with others and to give and accept respect; therefore it is called the second home. Schools are organizations designed to influence and promote cognitive development and behavioral change. Health education provided by teachers may have an immediate effect on students and continue to influence students' health behaviors into adulthood.

Strong beliefs among children and adolescents in the curative power of medicines [4], their limited knowledge about prevention and the easy accessibility to household medicines raises serious concerns. Since students spend most of their time in school with their teachers, proper education to the school teachers on the use of medicines will lead students toward a more rational and safer use of medicines. Self-medication among adolescents has become a serious problem that plays an important role in irrational use of medication and tends to increase with the age of adolescents [5,6]. A study done in Kuwait among school teachers, found that teachers considered teaching their students about the proper use of medicines so important that they felt it should be included in the national curriculum of health education [6].

Authors have consulted various reports and studies done within Nepal and outside [7-10] for identifying the problem areas in medicine use. A study done in Greece indicated irrational use of antibiotics and a need of exploring issues related to their use. This study explored parents' attitudes which often contribute to inappropriate prescription of antibiotics [10]. Similarly, another study done in Poland indicated that useful educational tools implemented in primary and secondary schools could play an important role in reducing the burden of community-acquired infections. The resource improves knowledge about microorganisms, hygiene and antimicrobial agents, and can be targeted at pupils, teachers and parents [11]. A pre-post comparison of a community intervention in Nepal has also shown the importance and benefits of educating school teachers and their impact on students [12].

Students at schools are taught various subjects including health and environmental health and science from class eight till class ten. Various topics taught are the human body, health and nutrition, physical education, health and physical fitness, community health and personal sanitation. Students are also given an orientation about common diseases. The topics of disease causing 'germs' and medicines which can be used to treat these diseases are also introduced. The information level about these topics gradually increases as the students progress through high school. About four to six hours are devoted to these topics every week. Teachers who teach these subjects have at least a Bachelor degree in biology.

Providing knowledge regarding use of medicine to school teachers is an important component of the overall health care delivery system of any country [13]. In developing countries such as Nepal where infant and early childhood mortality is high its importance cannot be overemphasized. For this reason the knowledge, attitude and practice among school teachers regarding use of medicines in Nepal needs to be evaluated. School teachers can help in rational use of medicines if they have the relevant information which can be transferred to students and through them to parents and the community.

The authors planned to study the knowledge, attitude and practice (KAP) regarding medicines among school teachers which is lacking in the Nepalese context. The association of KAP scores with demographic factors would help to identify subsections of teachers who may have deficiencies in knowledge and may need extra educational programs. In Nepal, there are various ethnic groups whose members have a common heritage, often consisting of a common language, a common culture often including a shared religion. The caste group is a system of social stratification in which communities are defined by thousands of endogamous hereditary groups called jatis. The jatis are formally grouped by the Brahminical texts under four well known categories, Brahmans (priests), Kshatriyas (kings, warriors, law enforcers, administrators), Vaishyas 
(agriculturists, cattle-herders and traders), and Shudras (lower caste menials, artisans, labourers, craftsmen, service providers) [14]. People belonging to the lower castes are disadvantaged and may have lesser knowledge and teachers from these disadvantaged groups have lesser opportunities for education compared to their counterparts. These people come from rural areas and face more hurdles. Lalitpur is one of the seventy-five districts of Nepal. The district, with Patan as its district headquarters, covers an area of $385 \mathrm{~km}^{2}$ and has a population (2001) of 337,785 . It is one of the three districts in the Kathmandu Valley, along with Kathmandu and Bhaktapur. Its population was 466,784 in the initial 2011 census tabulation. Lalitpur District has many famous schools, colleges and hotels [15].

In Nepal classes from 1-5 are considered as primary school. The main objective is to reach children to read, write and do arithmetic. Secondary education (classes 6-8), stresses personality development and trains the students for higher learning. Classes 9 and 10, upper secondary, serve as the stepping stone for the higher secondary level. Classes 8 to 10 are termed as high school. Classes 11 and 12 are regarded as higher secondary where students take up different streams of study. Science, humanities, and commerce are the main courses for higher secondary study. The private schools in general have better facilities, are better managed and show better performance in the school leaving certificate (SLC) examinations as compared to Government schools. Government schools get financial aid for running the educational programs and hence the school fees are lesser compared to the private ones [16].

Rationale of the study: Studies have revealed major misconceptions about and irrational use of medicines in different countries. Studies regarding the knowledge, attitude and practice (KAP) of medicines among school teachers are lacking in the Nepalese context. As teachers could play an important role in educating their students and are regarded as learned and respected persons in local communities it is important that they have proper knowledge about medicines. This knowledge can be transferred to their students, their parents and members of the community. Authors thought that it is important to obtain their baseline KAP so that strengths and deficiencies can be noted and appropriate educational interventions planned.

This study was carried out with the following objectives.

a. To obtain knowledge, attitude and practice about medicines among school teachers of selected schools in Lalitpur district.

b. To note the association of knowledge, attitude and practice with demographic and other characteristics of school teachers and

c. To compare KAP scores before and after an educational intervention.

\section{Method}

\section{Study duration}

April 2011 to December 2011.

\section{Study design \\ Prospective longitudinal.}

\section{Ethical considerations}

Teachers were informed about the aims and objectives of the study and invited to participate. Written informed consent was obtained from all participants. The study was approved by the Institutional Research Committee (IRC) of KIST Medical College. Teacher's knowledge, attitude and practice regarding medicines were studied using a questionnaire. A quasi-experimental study design with a control group which did not undergo the educational intervention would have reduced bias and made the study more powerful. This was not possible in our study as the school managements involved wanted all their teachers to benefit from the educational intervention. They were not in favor of denying a group of teachers the benefits of the intervention. As the teachers selected from each institution were those interested and willing to participate we were not sure about matching the respondents of the test and control group with regard to demographic characteristics. The issue was discussed during the review by and presentations before the experts of the UGC and the final study design was accepted and approved. The IRC of KIST Medical College also felt providing the educational intervention to all those involved would lessen the associated ethical problems.

\section{Study population}

Selected school teachers from both government and private schools in Lalitpur district, Nepal

\section{Sampling method}

Teachers selected were from primary and secondary levels of various government and private schools. Data about the schools in Lalitpur district were collected from the Lalitpur district education office. After obtaining this data, schools were chosen on the basis of their location. There are about 324 private and 198 government schools in Lalitpur district. We selected 17 schools from Lalitpur district. Out of these schools 11 schools were from urban areas and 6 schools were from rural areas. All the 11 schools from urban sector were private schools and the six government schools were from rural area. The sampling frame corresponded to distribution of schools in the district. Since the number of teachers in these private schools was more in the population (Lalitpur district), more teachers were included in the study sample. Specific schools from urban and rural areas were selected using random sampling method, i.e., lottery method. Total number 
of school teachers in the schools at Lalitpur district is approximately 21150. Among this, we selected 393 school teachers for our study.

\section{Sample size calculation}

For sample size calculation, we assumed that the knowledge should be about $50 \%$ in our population of school teachers. This has been tested by pilot test and also assumed from literature review.

Knowledge $=50 \%, \mathrm{P}=0.5, \mathrm{Q}=1-\mathrm{P}=0.5$

$$
\mathrm{N}=\mathrm{Z} \alpha^{2} \mathrm{xPxQ} /(\mathrm{M} . \mathrm{E} .)^{2}
$$

Where $\mathrm{Z} \alpha=1.96$ from normal table, two tailed

$\mathrm{P}=$ Population proportion

M.E = Margin of error

Now, $\mathrm{n}=(1.96)^{2} \times(0.5) \times(0.5) /(0.05)^{2}$

$=384$

Non response correction $=5 \%$

Total Sample size with provision for drop outs from the study $=384+5 \%$ of $384=403$

Since no teachers dropped out from the study as they were an easily traceable population and we selected only schools whose managements were supportive of the study the sample size should be adequate for the study purposes.

\section{Study instrument development}

The main objective of the study was to include questions based on the methodology of KAP studies about rational use of medicines conducted in other countries. Unfortunately literature about KAP of medicines among school teachers was scanty. To accomplish this goal, various health promotion models like the health belief model developed by Becker in the 1970s and Theories of reasoned action and planned behaviour developed in the 1980s by Ajzen and Fishbein and others were studied and applied emphasizing people's intentions to change their attitudes and beliefs [17]. The health belief model suggests that the likelihood of an individual taking action with regard to a health problem is based on their perceived susceptibility to a health problem, their belief about its potential serious consequences, their belief that a particular course of action will reduce the probable consequences and an analysis whether the benefits of taking action will outweigh the costs or consequences $[18,19]$. The effects of irrational use of medicines on individual health, health of their family members and the potential serious consequences were emphasized. With regard to medicines many of the consequences were long term and not always direct so it was a challenge addressing some of these. We emphasized the important role of school teachers in the community and their vital importance in improving community health and improving the use of medicines. Goodman and colleagues suggested a four-stage model of organizational change which is also applicable to health promotion [20]. Stage 1 is referred to as awareness raising and involves stimulating interest and raising awareness about the problem at a senior level and also exploring solutions. Our intervention mainly focused at this level and during the educational sessions senior management of the schools were also present. Stage 2 is adoption of the change, stage 3 is implementation while stage 4 is institutionalizing the change. These further stages can be taken up in future. The stages of change model was developed by Prochaska and DiClemente and as a person plans to change a behavior he moves through different stages termed as precontemplation, contemplation, preparation, action and maintenance [21]. Our intervention mainly focused on the first three stages and further interventions may be needed to take the intervention to the next stages.

Health literacy is equipping people with the capacity to meet their healthcare needs in a complex society. An individual with an adequate level of health literacy has the ability to address his/her own healthcare needs, those of the family and the community [22]. A recent integrated conceptual model of health literacy details competencies related to accessing, understanding, appraising and applying health information [23]. In our questionnaire and in the educational sessions we discussed sources of medicines information available to the public in Nepal, how to understand and appraise the information and how to communicate medicine information to students and the public. Teachers as a part of their profession and training are equipped with these skills which were further strengthened by the educational intervention with special emphasis on medicines.

Manuscripts and published papers describing similar research and methodological issues were also studied $[7,9,10,12]$. The questionnaire was developed after discussions and deliberations among the researchers. After finalizing the statements, they were further discussed with other faculty members of the same department for their valuable inputs. Inputs were also obtained from other researchers in the field and from referees selected by the University Grants Commission (UGC) during the presentations and deliberations for short listing of research proposals for funding and during the detailed presentation of the study after acceptance. The questionnaire was pilot tested. The questionnaire was originally developed in English and translated into Nepali for better understanding by target teachers from primary and secondary section of different schools. The translated statements were given to Nepali language subject teachers for language correction. The questionnaire used is shown as an Additional file 1.

\section{Pretesting of the questionnaire}

The questionnaire was pretested for readability and ease of understanding among twenty-two teachers. These teachers 
taught different grades like eight, nine and ten. Their data was not used in the study. Face and content validation of the measuring instrument was done by analyzing the data obtained from these teachers and corrections done where required. Cronbach's alpha was measured as an indication of the internal consistency of the questionnaire. The value was 0.76 indicating good internal consistency.

\section{Demographics}

Basic personal information like gender, age, ethnic/caste group, subjects taught in school, educational qualification and whether the respondent was originally from a village or town was noted.

\section{Scoring system used}

Knowledge and attitude were studied by noting respondent's agreement with a set of 28 statements using a Likerttype scale. The scoring system used was: $5=$ strongly agree with the statement, $4=$ agree, $3=$ neutral, $2=$ disagree and 1 = strongly disagree with the statement. The scores were reversed for negative statements. There were twenty statements for assessing knowledge with a maximum possible score of 100 and eight statements for attitude with a maximum possible score of 40 . The practice component was measured by noting how often during the past month the respondent carried out a set of activities. Not at all was given the score 40,1-2 times was scored 30, 3-5 times as 20 , and more than 6 times as 10. The maximum score for practice part was 320 . The practice pattern covered areas like the frequency of use of medicines like antibiotics, vitamins and tonics, checking expiry dates before purchasing medicine, giving medicines to students, taking a cough syrup, treating fellow staff members or giving advice about medicines. The total scores before and after the module was obtained by adding the 'Knowledge', 'Attitude' and 'Practice' scores. The maximum total score was 380. The median total 'Knowledge,' 'Attitude', 'Skills', overall scores, and interquartile range were calculated. The questionnaire addressed different aspects about medicines like use of vitamins and tonics, deworming medicines, use of injections, cost of medicines, knowledge about expiry date, suspensions, controlled release preparations among others. The topics to be included in the questionnaire were developed on the basis of review of literature $[7,8,12]$ and the authors' experience of important medicine use problems in Nepal. Inputs were also obtained from other experts in the field.

To avoid bias certain statements were negative and their scores were reversed while calculating the total score. Knowledge, attitude and practice scores were compared before and after the intervention.

\section{Conduct of the study}

School managements supportive of the study were selected and all interested teachers from primary and secondary levels in selected schools were involved in the research. The school management allotted a certain time period where the authors could interact with the teachers, administer the questionnaires and educate them about selected aspects of medicines.

This study was done in two phases. During the first phase the KAP of school teachers was studied before the educational intervention and the second phase was after intervention in the same group. The time interval between the first phase of the study and the intervention part of the study was fifteen days but was sometimes modified and delayed as per the convenience of the school management and availability of time for the researchers.

The intervention sessions included a training session, an hour long presentation on important issues related to medicines followed by a session using posters where we provided participants with the necessary information regarding medicines. The subject areas covered during the sessions were those where participants had less knowledge, poor attitude and/or practice as identified from responses to the questionnaire. The poster session focused on areas like antibiotic resistance, information about medicine labels and expiry dates. The prepared medicine information leaflets were distributed to all the study participants. The information leaflets dealt with reading label of a medicine, knowing about adverse drug reactions and side effects of drugs, appropriate use of antibiotics etc. Inputs about the process to be followed and topics to be discussed during the intervention process was obtained from medical educators in the institution, other researchers working in the field in the country, different health promotion theories [17,18], studies [7,19] and expert reviewers of the University Grants Commission who reviewed the study proposal and provided constructive comments. Two of the authors NJ and OB acted as facilitators for the intervention sessions with PRS who has advanced training in medical education providing critical inputs and support.

\section{Statistical analysis}

After the intervention, the KAP scores were again measured using the same questionnaire. The collected data were analyzed using SPSS 17.0 for Windows. The knowledge, attitude and practice scores and total scores before and after the educational intervention were tested for normality of distribution using one sample KolmogorovSmirnov test. The samples were noted not to follow a normal distribution and median was calculated as a measure of central tendency, interquartile range as measure of variance and non-parametric tests were used for comparison between different subgroups of respondents pre-intervention. Scores before and after the intervention were compared using the Wilcoxon signed ranks test. Median knowledge, attitude, practice and total scores were compared among 
different subgroups of respondents with regard to variables like gender, age, ethnicity, educational qualification, government and private schools, subjects taught, and educational level being taught like primary and secondary level before and after the intervention using the Mann-Whitney test for dichotomous variables and Kruskal Wallis test when there was more than two subgroups of respondents. A p value less than 0.05 was taken as statistically significant.

\section{Results}

\section{Respondent demographics}

A total of 393 teachers participated before and after intervention. One hundred and ninety-one (50.1\%) were male and 190 (49.9\%) were female. There were 190 participants from the age group 21-30 years (49.9\%) followed by 104 (27.3\%) from the age group of 31-40. Two hundred and fifteen (57.5\%) teachers were from primary level and 159 $(42.5 \%)$ teachers were from secondary and higher secondary level. Majority of participants were Newars followed by Chettris. Most of the teachers were teaching Maths followed by English. Maximum teachers were holding bachelor degree followed by master's degree. Two hundred and fifty-eight (65.6\%) teachers were from private schools and 135 (34.4\%) were from government schools. The total of different subgroups may not add up to 393 as certain respondents did not fill in all the required information. Table 1 shows the demographic characteristics of the respondents.

\section{KAP scores}

The median (interquartile range) knowledge, attitude and practice scores before the intervention were $63(10)$, 23 (5) and 270 (48) respectively while the median overall score was 356 . The median (interquartile range) knowledge, attitude and practice scores after the intervention were 71 (10), 28 (5) and 270 (48) respectively while the overall median score increased to 369 . Maximum possible score of knowledge, attitude and practice were 100 and 40 and 320 respectively. By using the Wilcoxon signed ranks test, knowledge $(\mathrm{p}<0.001)$, attitude $(\mathrm{p}<0.001)$ and total scores $(p<0.001)$ increased after the intervention but the practice score did not improve $(\mathrm{p}=0.528)$.

The scores of certain statements for example 'The term drugs and medicine are same,' 'Injections cure diseases more quickly than orally taken medicines', 'Deworming tablets should be taken by chewing,' 'Jeevan jal is not a powerful medicine as it is cheap', 'One drug can modify or alter the action of another drug,' 'Medicines should not be used after their expiry date,' 'All medicines cannot be used in case of pregnancy' and 'Suspensions need to be shaken well before use' were low before intervention. These scores increased post-intervention (Table 2).

Table 2 compares the median 'Knowledge', 'Attitude', 'Practice' and total scores at the beginning and end of the
Table 1 Demographic characteristics of the respondents

\begin{tabular}{|c|c|}
\hline \multirow[t]{2}{*}{ Characteristic } & Number (percentage) \\
\hline & $n=393$ \\
\hline \multicolumn{2}{|l|}{ Gender } \\
\hline Male & $191(48.6)$ \\
\hline Female & $190(48.3)$ \\
\hline Not mentioned & $12(3.1)$ \\
\hline \multicolumn{2}{|l|}{ Age } \\
\hline Below 20 & $6(1.5)$ \\
\hline $21-30$ & $190(48.3)$ \\
\hline $31-40$ & $104(26.5)$ \\
\hline $41-50$ & $74(18.8)$ \\
\hline $51-60$ & $7(1.8)$ \\
\hline Above 60 & $3(0.8)$ \\
\hline Not mentioned & $9(2.3)$ \\
\hline \multicolumn{2}{|l|}{ Teachers } \\
\hline Primary & $215(54.7)$ \\
\hline Secondary & $159(40.5)$ \\
\hline Not mentioned & $19(4.8)$ \\
\hline \multicolumn{2}{|l|}{ Ethnic/caste Group } \\
\hline Brahmin & $56(14.2)$ \\
\hline Chettri & $106(27.0)$ \\
\hline Newar & $145(36.9)$ \\
\hline Janajati & $40(10.2)$ \\
\hline Not mentioned & $46(11.7)$ \\
\hline \multicolumn{2}{|l|}{ Subjects } \\
\hline Nepali & $49(12.5)$ \\
\hline Science & 45 (11.5) \\
\hline Maths & $105(26.7)$ \\
\hline English & $80(20.4)$ \\
\hline Others & $100(25.4)$ \\
\hline Not mentioned & $14(3.5)$ \\
\hline \multicolumn{2}{|l|}{ Qualification } \\
\hline Intermediate & $20(5.1)$ \\
\hline Bachelors & $225(57.3)$ \\
\hline Masters & $126(32.1)$ \\
\hline Not mentioned & $22(5.6)$ \\
\hline \multicolumn{2}{|l|}{ Type of school } \\
\hline Private & $258(65.6)$ \\
\hline Government & $135(34.4)$ \\
\hline
\end{tabular}

intervention. The scores were significantly higher at the end of the intervention for knowledge, attitude and total scores.

Table 3 compares the median total scores among various subgroups of respondents both before and after intervention. 
Table 2 Median knowledge, attitude, practice and overall scores before and after intervention

\begin{tabular}{lll}
\hline Characteristic & Median score & P-value \\
\hline Attitude & 23 & $<0.001$ \\
Before Intervention & 28 & \\
After Intervention & & $<0.001$ \\
Knowledge & 63 & \\
Before Intervention & 71 & 0.528 \\
After Intervention & & \\
Practice & 270 & \\
Before Intervention & 270 & $<0.001$ \\
After Intervention & & \\
Total score & 354 & \\
Before Intervention & 365 & \\
After Intervention &
\end{tabular}

The scores before and after the intervention were compared using Wilcoxon signed ranks test.

\section{The scores of different subgroups of respondents before} the intervention

\section{Knowledge}

The scores for knowledge were same for both the male and female respondents. Similarly, the scores were same for all the age group respondents except the age group 41-50 years. The teachers from primary and secondary levels had the same knowledge scores. Teachers from other ethnic backgrounds had higher scores for knowledge. Teachers teaching different subjects were also having the same scores for knowledge whereas the scores were slightly less for teachers having intermediate and master's degree qualification compared to those with a bachelor's degree. Government school teachers were found to have higher scores compared to private school teachers.

\section{Attitude}

The scores for attitude were the same for both genders. Teachers with age less than 20 years and in the age group 51-60 years showed lower scores compared to other age groups. Primary and secondary level teachers had the same attitude score. Teachers teaching different subjects showed variation in the scores. Teachers teaching English and subjects other than science, maths and Nepali had lower attitude scores. There was no difference in the scores for attitude among teachers according to qualifications. The attitude score was slightly higher among private school teachers.

\section{Practice}

Practice scores revealed that females were having better scores as compared to males. Teachers from the age group 31-40 years had lower scores as compared to other age groups. Primary and secondary level teachers had the same scores while teachers from the Newar ethnic group had lower scores compared to other ethnic groups. Teachers teaching different subjects showed the same scores except teachers teaching other subjects whose score was 265 . Government and private school teachers had the same scores.

\section{Comparison of scores before and after intervention of various subgroups of respondents}

Table 3 mentions scores among subgroups of respondents both before and after the intervention.

\section{Knowledge}

The knowledge scores improved significantly among females compared to males. The scores improved from 63 to 72 . Similarly, the scores for knowledge were significantly improved for primary as well as secondary teachers after the intervention. Teachers from the caste group Chettris and other groups showed a significant improvement of knowledge after the educational intervention. Teachers with masters and bachelor level of qualification showed greater improvement in the knowledge scores compared to teachers having intermediate level of qualification. Private school teachers showed better scores than the government school teachers.

\section{Attitude}

Males and females showed a significant change in their attitude about the use of medicines post intervention. All age group respondents showed an improvement in the scores which was statistically significant. Similarly, teachers from different ethnic backgrounds showed a significant improvement in the scores. Teachers teaching different subjects also showed similar type of improvement in the scores. Teachers having higher level of education showed more improvement in the attitude scores and both the government and private school teachers showed a significant improvement in scores.

\section{Practice}

The increase compared to before the intervention was significant among the age group 41-50 years and 51-60 years. The increase if any among other subgroups of respondents was not statistically significant.

\section{Discussion}

The overall median knowledge, attitude and total scores improved significantly post-intervention. Differences in KAP scores were noted among certain groups of respondents both before and after the intervention.

\section{Knowledge}

The teachers who participated in our study represent different caste and ethnic groups of Nepal like Brahmins, 
Table 3 Comparison of median scores among different subgroups of respondents before and after intervention

\begin{tabular}{|c|c|c|c|c|c|c|c|c|c|c|c|c|}
\hline \multirow[t]{2}{*}{ Characteristic } & \multicolumn{3}{|c|}{ Knowledge } & \multicolumn{3}{|c|}{ Attitude } & \multicolumn{3}{|c|}{ Practice } & \multicolumn{3}{|c|}{ Total } \\
\hline & Before & After & $P$ value & Before & After & $P$ value & Before & After & $P$ value & Before & After & $P$ value \\
\hline \multicolumn{13}{|l|}{ Gender $^{*}$} \\
\hline Male & 63 & 70 & $<0.001$ & 23 & 28 & $<0.001$ & 262 & 270 & 0.378 & 352 & 365 & $<0.001$ \\
\hline Female & 63 & 72 & 0.001 & 23 & 28 & $<0.001$ & 270 & 270 & 0.277 & 356 & 366 & $<0.001$ \\
\hline \multicolumn{13}{|l|}{ Age (in years) ${ }^{\Delta}$} \\
\hline Below 20 & 63 & 55.5 & 0.805 & 21.5 & 28.5 & 0.015 & 270 & 270 & 0.592 & 349 & 364 & 0.144 \\
\hline $21-30$ & 63 & 70 & $<0.001$ & 23 & 29 & $<0.001$ & 270 & 260 & 0.547 & 356 & 358 & 0.046 \\
\hline $31-40$ & 63 & 70 & $<0.001$ & 23 & 27 & $<0.001$ & 260 & 270 & 0.159 & 346 & 372 & $<0.001$ \\
\hline $41-50$ & 61.5 & 71 & $<0.001$ & 23 & 27 & $<0.001$ & 270 & 280 & 0.006 & 356 & 378.5 & $<0.001$ \\
\hline $51-60$ & 63 & 70 & 0.949 & 22 & 23 & 1.000 & 290 & 210 & 0.027 & 363 & 286 & 0.062 \\
\hline \multicolumn{13}{|l|}{ Teachers $^{*}$} \\
\hline Primary & 63 & 72 & $<0.001$ & 23 & 28 & $<0.001$ & 270 & 270 & 0.440 & 351 & 366 & $<0.001$ \\
\hline Secondary & 63 & 72 & $<0.001$ & 24 & 28 & $<0.001$ & 270 & 270 & 0.423 & 350 & 365 & $<0.001$ \\
\hline \multicolumn{13}{|c|}{ Ethnic/Caste group ${ }^{\Delta}$} \\
\hline Brahmin & 63 & 71.5 & $<0.001$ & 23 & 29 & $<0.001$ & 260 & 270 & 0.457 & 348 & 372 & 0.004 \\
\hline Chettri & 63 & 74 & $<0.001$ & 23 & 28 & $<0.001$ & 260 & 270 & 0.509 & 351 & 372 & $<0.001$ \\
\hline Newar & 63 & 68 & $<0.001$ & 23 & 27 & $<0.001$ & 210 & 270 & 0.309 & 353 & 363 & 0.030 \\
\hline Others & 64 & 74 & $<0.001$ & 23 & 28 & $<0.001$ & 260 & 270 & 0.665 & 325 & 355 & 0.411 \\
\hline \multicolumn{13}{|l|}{ Subject taught ${ }^{\Delta}$} \\
\hline Nepali & 63 & 70 & $<0.001$ & 23 & 29 & $<0.001$ & 270 & 270 & 0.457 & 355 & 372 & 0.031 \\
\hline Science & 63 & 73 & $<0.001$ & 23 & 29 & $<0.001$ & 270 & 290 & 0.455 & 352 & 385 & 0.001 \\
\hline Math & 63 & 72 & $<0.001$ & 24 & 29 & $<0.001$ & 270 & 270 & 0.576 & 357 & 365 & 0.211 \\
\hline English & 63 & 67 & $<0.001$ & 22 & 26.5 & $<0.001$ & 270 & 270 & 0.945 & 356 & 356 & 0.224 \\
\hline Others & 62.5 & 72 & $<0.001$ & 22.5 & 27 & $<0.001$ & 265 & 275 & 0.157 & 349.5 & 371 & $<0.001$ \\
\hline \multicolumn{13}{|l|}{ Qualifications $^{\Delta}$} \\
\hline Intermediate & 62.5 & 69 & 0.223 & 23 & 23 & 0.017 & 255 & 270 & 0.895 & 337 & 346 & 0.845 \\
\hline Bachelor & 63 & 70 & $<0.001$ & 23 & 28 & $<0.001$ & 270 & 270 & 0.281 & 353 & 362 & $<0.001$ \\
\hline Master & 62.5 & 71 & $<0.001$ & 23 & 28.5 & $<0.001$ & 270 & 270 & 0.452 & 359 & 371 & $<0.001$ \\
\hline \multicolumn{13}{|l|}{ Type of school ${ }^{*}$} \\
\hline Government & 66 & 70 & $<0.004$ & 22 & 28 & $<0.001$ & 230 & 270 & 0.148 & 321 & 359 & $<0.001$ \\
\hline Private & 63 & 71 & $<0.001$ & 23 & 28 & $<0.001$ & 270 & 270 & 0.071 & 357 & 369 & $<0.001$ \\
\hline
\end{tabular}

*Mann-Whitney test was used as there were only two subgroups in this category.

$\Delta$ Kruskal Wallis test was used as there were more than two subgroups in this category.

Chettris, Newars, and Janajatis (Tharus, Limbus, Magars, Madhesis etc.) The median score for all castes improved after the intervention but significantly for chettris though Brahmins are still at the top of the caste hierarchy and have been considered to be highly intellectual since ancient times. Teachers coming from other ethnic groups are also called as Janajatis, who are the indigenous people of Nepal who have been traditionally oppressed and had low status in a caste dominated society. These teachers also have shown a significant improvement of knowledge. Recently seats have been reserved for them in educational institutions [14]. Scores also improved post-intervention according to educational qualification of teachers. This improvement was seen to be more significant in teachers with a higher level of education. Knowledge improvement has been shown to be associated with level of education in previous studies. A study done in Iran showed that the pregnant women's knowledge about the use of folic acid and iron supplements had a significant relationship with the level of education [24]. In a recent study conducted among pharmacists regarding knowledge and attitudes toward herbal medicine, the median knowledge scores improved after the educational intervention [25].

Maximum number of schools in Lalitpur district is run by the private sector and comparatively less number of schools is run by the government. So more number of 
teachers were enrolled from private schools in our study. The result showed that there was improvement in the knowledge scores for private school teachers.

\section{Attitude}

The attitude improved among males and female respondents. Similarly, teachers coming from all the ethnic backgrounds had significant improvement in the scores. This may be due to the changing scenario with people from different ethnic backgrounds now obtaining more facilities for education and growth. The median attitude and total scores improved after the intervention for all the age groups and teachers coming from different levels of government and private schools.

Attitudes or belief refers to traditional ideas, which are erroneous from an individual's perspective, and this forms obstacles to appropriate behavior and treatmentseeking practices [26]. Attitude can be proper or improper. Proper attitudes can improve practice while improper attitudes can have a harmful effect. Measuring practice is a part of a standard KAP survey questionnaire. However, many KAP studies do not present results regarding attitudes and practices appropriately, probably because people may not express their real thoughts, beliefs and understandings which may be misinterpreted towards a particular subject area. This may have a direct impact on an individual's thoughts [27].

\section{Practice}

Practice has a direct impact on an individual's behavior and change in practice can be obtained by carrying out more educational interventions for improving people's practice.

Our study showed no improvement in the practice scores. A study done to evaluate knowledge, attitude and practice of self-medication among first year medical students in Bahrain showed that the practice for common over the counter medicines were not proper and were often inappropriate. This showed that even medical students do not have proper practice regarding safe use of medicines [28].

The reason behind this may be the duration of our educational intervention. Since, our intervention was for a short duration it may not be sufficient for substantial improvement in participant's overall knowledge, attitude and practice level. Practice may be improved only after substantial changes in the knowledge and attitude level. Another problem about the practice part is the retention of the educational intervention provided to the participants. The educational intervention was conducted only once and was not repeated. The effect of the intervention on retention of information was not assessed. Lack of centers and information sources from where consumers can obtain unbiased, impartial knowledge about medicines may be another limitation which could have influenced practice.

\section{Queries from participants}

Participants in the training session wanted more information about the duration and frequency of antibiotic use. They wanted detailed information about the use of herbal medicines and their safety profile. Some of the participants had a query about the beneficial and harmful effects after switching over to another brand of the same generic. Certain female participants were interested to know about the frequency of using anthelminthics for their child. Few questions were asked about the use of vitamins and tonics without any defined clinical indications. Vitamin supplements are commonly used with or without prescription by individuals for various reasons as an over the counter medicines. Certain participants did not know about the harmful effects of overuse of vitamins. This was very similar to a study done in Karachi, where knowledge, attitude and practice regarding the use of vitamin supplementation among patients visiting out-patient physicians were assessed was the most frequently raised question by the teachers. They were more concerned for the use of vitamins as a dietary supplement [29]. A similar type of study done at Nepal also revealed that the effect of intervention was associated with a significant increase in correct knowledge about action of antibiotics and excellent knowledge on methods of administration of antibiotics. The intervention was associated with a significant increase in knowledge on source of vitamins, and use of vitamin/tonics [12].

Dose of paracetamol and the use of its suspension was one of the commonest questions asked by female participants. Maximum number of participants agreed that they check the expiry dates prior to using a medicine and iron and folic acid should be given to pregnant women.

\section{Strength of the study}

This study explores an area which has not previously been studied in Nepal to the best of our knowledge. It helps to understand the importance of knowledge transfer to the teachers and how the change in knowledge, attitude and practice can improve medicine use. This study enables lay persons to understand the importance of medicines like, antibiotics, deworming tablets, injections use and other important issues related to use of medicines.

\section{Recommendations}

More studies are required so that detailed information about knowledge, attitude and practice are required. More resource intensive educational sessions are needed for better use of medicines by the consumers in a developing country like Nepal. Short training sessions or workshops 
should be arranged specifically for consumers like patients, school and college teachers to educate them about the safe and rational use of medicines. Further studies among a larger population of school teachers are required.

\section{Limitations}

Our study had limitations. There was the problem of obtaining convenient time slots for conducting the study from school teachers and school management out of their busy schedule. Frequent shutdowns limited and hindered access to the study sites. Similarly, lack of free time for teachers apart from their normal duty hours was also a limitation. Besides, we could not gather all the teachers simultaneously for educational sessions due to various constraints. Certain schools were not responsive towards the study. We also did not employ a quasiexperimental study design employing a control group. The sample size was adequate but the number of teachers in certain subgroups was low.

\section{Conclusions}

Knowledge, attitude and practice regarding medicines were noted among a sample of school teachers. Their association with demographics was measured. The scores were compared before and after the educational intervention. An educational intervention using different methods was found to be effective in significantly improving knowledge, attitude and total scores. Since, the intervention was carried out only once its effect on retention of knowledge was not measured. The practice scores were not significantly improved. More interventional research is needed on widely prescribed and utilized drugs and also on self-medication.

\section{Additional file}

Additional file 1: Questionnaire for obtaining knowledge, attitude and practice towards medicines among school teachers in Nepal.

\section{Competing interests}

The authors declare that they have no competing interests.

\begin{abstract}
Authors' contributions
NJ was involved in conducting the study, conceptualizing the study, designing the questionnaire, collecting the data, reviewing the literature and writing the manuscript. OB helped in conducting the educational intervention, conceptualizing the study, designing the questionnaire, collecting the data, reviewing the literature performing the statistical analysis. PRS helped in conceptualizing the study, finalizing the methodology, performing statistical analysis and writing the manuscript. All authors have read and approved the final submitted version of the manuscript.
\end{abstract}

\section{Acknowledgements}

We thank Mr. Shital Bhandary, Biostatistician and Assistant Professor Community Medicine, Patan Academy of Health Sciences for his help with statistics. We also thank to Mr. Ram Bahadur Kuwar, Lecturer, Department of Anatomy for his help for conducting the initial stage of the study. We also acknowledge the help from Mr. Kshitiz Upadhya Dhungel for the language corrections while translating the questionnaire into Nepali. The authors are grateful for the financial help from University Grants Commission (UGC), Sanothimi, Nepal for conducting the study. We would like to thank all the teachers who participated in the study and to our fellow colleagues in the department for their kind support.

\section{Author details}

${ }^{1}$ Department of Clinical Pharmacology \& Therapeutics Department of Clinical Pharmacology \& Therapeutics, KIST Medical College, Imadol, Nepal. ${ }^{2}$ KIST Medical College, Imadol, Nepal. ${ }^{3}$ Department of Clinical Pharmacology \& Therapeutics, KIST Medical College, Imadol, Nepal.

Received: 26 September 2012 Accepted: 11 July 2013

Published: 13 July 2013

\section{References}

1. World Health Organization Media Centre: Promoting rational use of medicines saves lives and money, WHO experts say. http://www.who.int/ mediacentre/news/notes/2004/np9/en/.

2. World Health Organization: Antimicrobial resistance-food borne disease surveillance; 2001. http://www.who.int/foodborne_disease/resistance/en/

3. Fresle $D$, Wolfheim $C$ : Public education in rational drug use a global survey. WHO; 1997. www.who.int/medicinedocs/pdf/s2235e/s2235e.pdf.

4. Oforwe GE, Ofili AN: Knowledge, attitude and practice of school health programme among head teachers of primary schools in Egor local government area of Edo state. Ann Afr Med 2007, 8:32-37.

5. Bozoni K, Kalmanti M, Koukouli S: Perception and knowledge of medicines of primary schoolchildren: the influence of age and socioeconomic status. Eur J Pediatr 2006, 165:42-49.

6. Abahussain E, Matowe LK, Nicholls PJ: Self-reported medication use among adolescents in Kuwait. Med Princ Pract 2005, 14:161-164.

7. World Health Organization: The role of education in the rational use of medicines; 2006. http://apps.who.int/medicinedocs/documents/s16792e/s16792e.pdf.

8. Holloway KA, Karkee SB, Tamang AL, Gurung YB, Kafle KK, Pradhan R: Community intervention to promote rational treatment of acute respiratory infection in rural Nepal. Trop Med Int Health 2009, 14:101-110.

9. Grand A, Hogerzeil H, Haaijer F: Intervention research in rational use of drugs: a review. Health Policy Plan 1999, 14:89-102.

10. Panagakou SG, Spyridis N, Papaevangelou V, Theodoridou KM, Goutziana GP, Theodoridou MN, Syrogiannopoulos GA, Hadjichristodoulou CS: Antibiotic use for upper respiratory tract infections in children: a cross-sectional survey of knowledge, attitudes, and practices (KAP) of parents in Greece. BMC Pediatr 2011, 11:60.

11. Olczak PA, Grzesiowski P: Progress towards implementing the e-bug project in Poland. J Antimicrob Chemother 2011, 66(Suppl 5):77-79.

12. Kafle KK, Karkee SB, Shrestha N, Prasad RR, Bhuju GB, Das PL, Chataut BD: Community intervention to improve knowledge and practices on commonly used drugs. Kathmandu Univ Med J 2010, 29:29-34.

13. Anttila KH, Juvonen M, Ahonen R, Bush PJ, Airaksinen M: What schoolchildren should be taught about medicines: combined opinions of children and teachers. Health Educ 2005, 105:424-436. http://www. emeraldinsight.com/journals.htm?articleid $=1528682$.

14. Lynn B, Dahal DR, Govindasamy PAV: Caste, ethnic and regional identity in Nepal: further analysis of the $2006 \mathrm{Nepal}$ demographic and health survey. Calverton, Maryland, USA: Macro International Inc; 2008. www.measuredhs. com/pubs/pdf/FA58/FA58.pdf.

15. Wikipedia database, Lalitpur district, Nepal. http://en.wikipedia.org/wiki/ Lalitpur_District,_Nepal.

16. The education system in Nepal. http://www.spainexchange.com/guide/NPeducation.htm.

17. Ajzen I, Fishbein M: Understanding attitudes and predicting social behavior. New Jersey: Prentice-Hall; 1980.

18. Janz NK, Becker MH: The health belief model: a decade later. Health Educ Behav 1984, 11:1-47.

19. Davies M, MacDowall W: Health promotion theory. London: Open University Press; 2006.

20. Goodman RM, Steckler A, Kegler MC: Mobilising organizations for health enhancement: theories of organizational change. Health behaviour and health education: theory, research and practice. San Francisco: Jossey-Bass; 2002.

21. Prochaska JO, DiClemente CC: Stages and processes of self-change of smoking: Toward an integrative model of change. J Consult Clin Psychol 1983, 51:390-395. 
22. McQueen DV, Kickbusch I, Potvin L, Pelikan JM, Balbo L, Abel T: Health and modernity- The role of theory in health promotion. New York: Springer; 2007.

23. Sorenson K, Van Den Broucke S, Fullam J, Doyle G, Pelikan J, Slonska Z, Brand $\mathrm{H}$ : Health literacy and public health: a systematic review and integration of definitions and models. BMC Publ Health 2012, 12:80.

24. Moradi F, Mohammadi S, Kadivar AA, Masoumi SJ: Knowledge and practice of pregnant women in Fars province about intake of iron supplements. Acta Med Iran 2007, 45:301-304.

25. Chang ZG, Kennedy DT, Holdford DA, Small RE: Pharmacists' knowledge and attitudes toward herbal medicine. Ann Pharmacother 2000, 34:710-715.

26. Cleland J: A critique of KAP studies and some suggestions for their improvement. Stud Fam Plann 1973, 4:42-47.

27. Good B: Medicine, rationality and experience: An anthropological perspective. Cambridge: Cambridge University Press; 1993.

28. Henry J, Handu SS, Al Khaja KA, Otoom S, Sequeira RP: Evaluation of the knowledge, attitude and practice of self-medication among first-year medical students. Med Princ Pract 2006, 15:270-275. http://www.karger. com/Article/FullText/92989.

29. Qidwai W, Samani ZA, Azam I, Lalani S: Knowledge, attitude and practice of vitamin supplementation among patients visiting out-patient physicians in a teaching hospital in Karachi. Oman Med J 2012, 27:116-120.

doi:10.1186/1471-2458-13-652

Cite this article as: Jha et al:: Knowledge, attitude and practice towards medicines among school teachers in Lalitpur district, Nepal before and after an educational intervention. BMC Public Health 2013 13:652.

\section{Submit your next manuscript to BioMed Central and take full advantage of:}

- Convenient online submission

- Thorough peer review

- No space constraints or color figure charges

- Immediate publication on acceptance

- Inclusion in PubMed, CAS, Scopus and Google Scholar

- Research which is freely available for redistribution 